\title{
Life threatening hemobilia after endoscopic retrograde cholangiopancreatography (ERCP)
}

Ihab I. El Hajj, MD, MPH, ${ }^{1}$ Stuart Sherman, MD, ${ }^{1}$ Maximilian Pyko, DO, ${ }^{2}$ Glen A. Lehman, $\mathrm{MD},{ }^{1}$

${ }^{1}$ Department of Internal Medicine, Division of Gastroenterology and Hepatology, Indiana University School of Medicine, Indianapolis, IN

${ }^{2}$ Department of Interventional Radiology, Indiana University School of Medicine, Indianapolis, IN

\section{Corresponding author:}

Ihab I. El Hajj, MD, MPH

Assistant Professor of Medicine

Indiana University School of Medicine

550 N University Blvd, Suite 1634E

Indianapolis, IN 46204

Phone: $317-274-3255$

Fax: 317-948-0164

Email: ielhajj@iu.edu

Word count: 220

A 55-year-old woman presented to the local community hospital with acute cholangitis. She underwent ERCP, biliary sphincterotomy, incomplete stone extraction, and plastic stent placement. ERCP was complicated by profuse GI bleed. Patient was intubated and resuscitated. Repeat ERCP noted bright red blood and blood clots actively exiting the biliary orifice. Sphincterotomy bleed was suspected. Endotherapy was performed followed by deployment of a fully covered self-expandable metal stent (FC-SEMS) across the papilla. The patient continued to bleed profusely and required multiple transfusions with PRBCs. She was then life-flighted to our medical ICU. She had multiple maroon stools with large blood clots, and expelled the FC- 
SEMS in her stools (Fig. 1). Urgent CT angiography showed active extravasation of contrast into the stomach, small bowel, and common bile duct (CBD) [dilated at $16 \mathrm{~mm}$ with multiple filling defects] (Fig. 2A). In view of these findings and the limitations of further endoscopic therapy, patient underwent hepatic selective angiography. This showed active extravasation of contrast from a pseudoaneurysm of the right hepatic artery (RHA). Contrast filled the CBD and flowed freely into the second duodenum (D2) (Fig. 2B). Area was successfully stented with 2 stent grafts (Fig. 2C). The patient recovered well with no bleeding recurrence.

Arterial vascular complication from ERCP is exceedingly rare [1]. Angiography has replaced surgery as the most useful diagnostic and therapeutic modality for massive arterial gastrointestinal bleed.

\section{Disclosures:}

Financial disclosure: None to report.

Informed consent was obtained from the patient to publish these images.

\section{CONFLICT OF INTERREST}

Conflict of interest: None to report.

Financial disclosure: None to report.

Informed consent was obtained for this case report.

\section{References}

[1].Espinel J, Pinedo E, Rascarachi G, et al. Exceptional vascular complication during ERCP: cannulation of the hepatic artery. Rev Esp Enferm Dig 2011;103:164-5. 


\section{FIG 1}

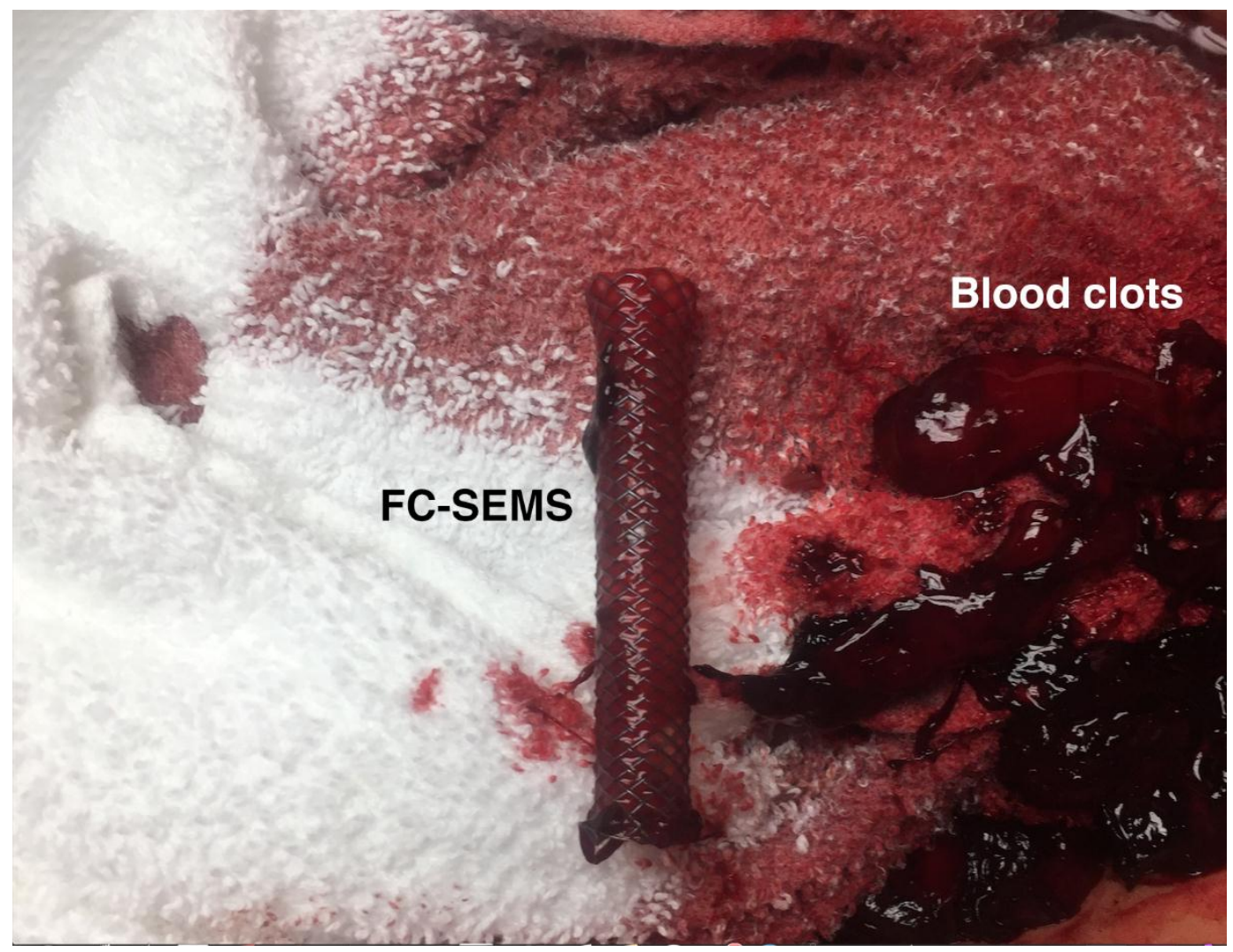


FIG 2 2a,2b,2c
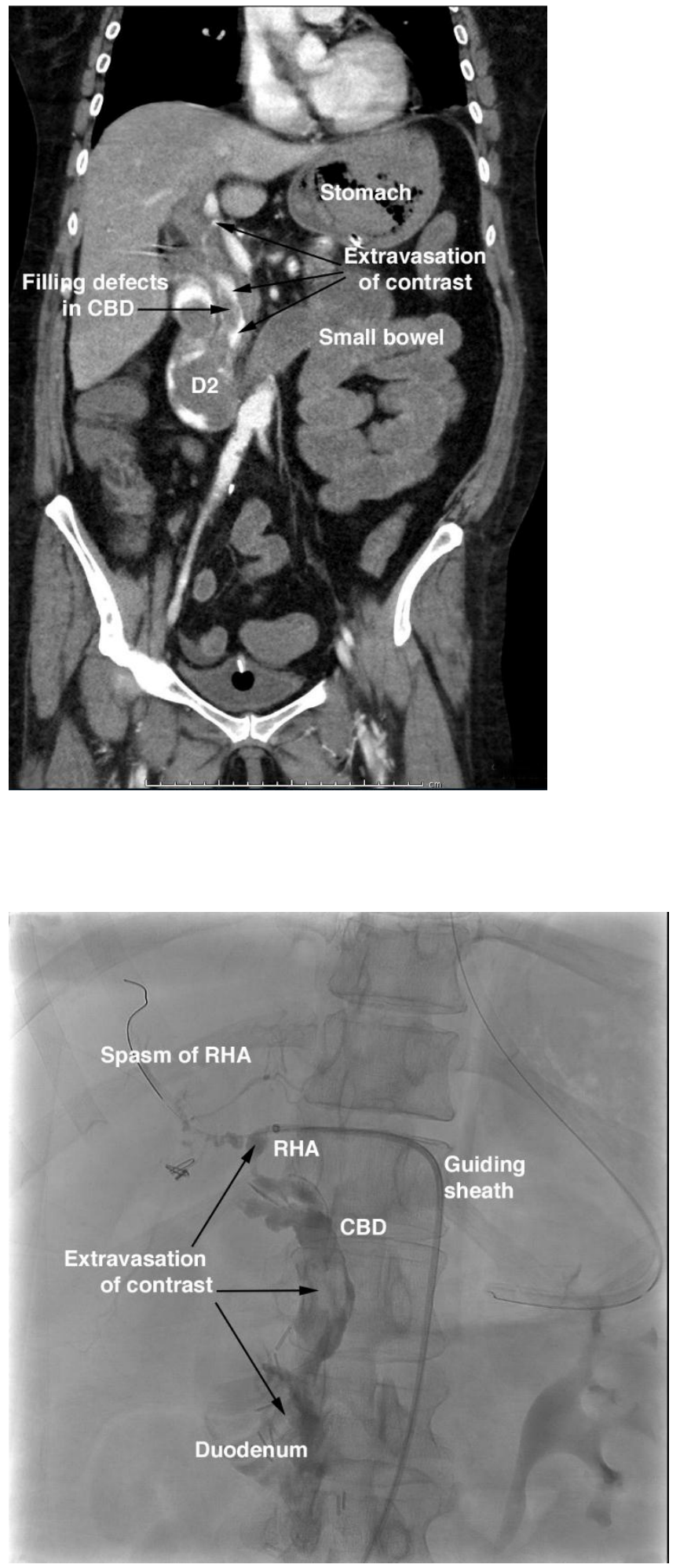

Downloaded for Anonymous User (n/a) at Indiana University - Ruth Lilly Medical Library from ClinicalKey.com by Elsevier on September $14,2017$. For personal use only. No other uses without permission. Copyright @2017. Elsevier Inc. All rights reserved. 


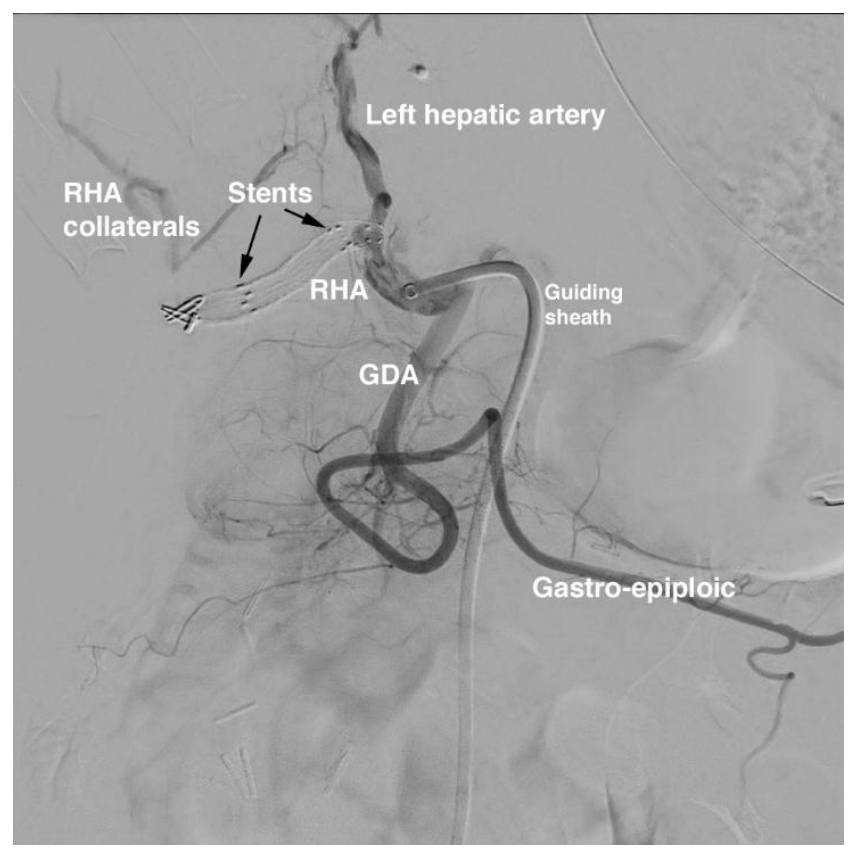

Downloaded for Anonymous User (n/a) at Indiana University - Ruth Lilly Medical Library from ClinicalKey.com by Elsevier on September 14, 2017. For personal use only. No other uses without permission. Copyright @2017. Elsevier Inc. All rights reserved. 